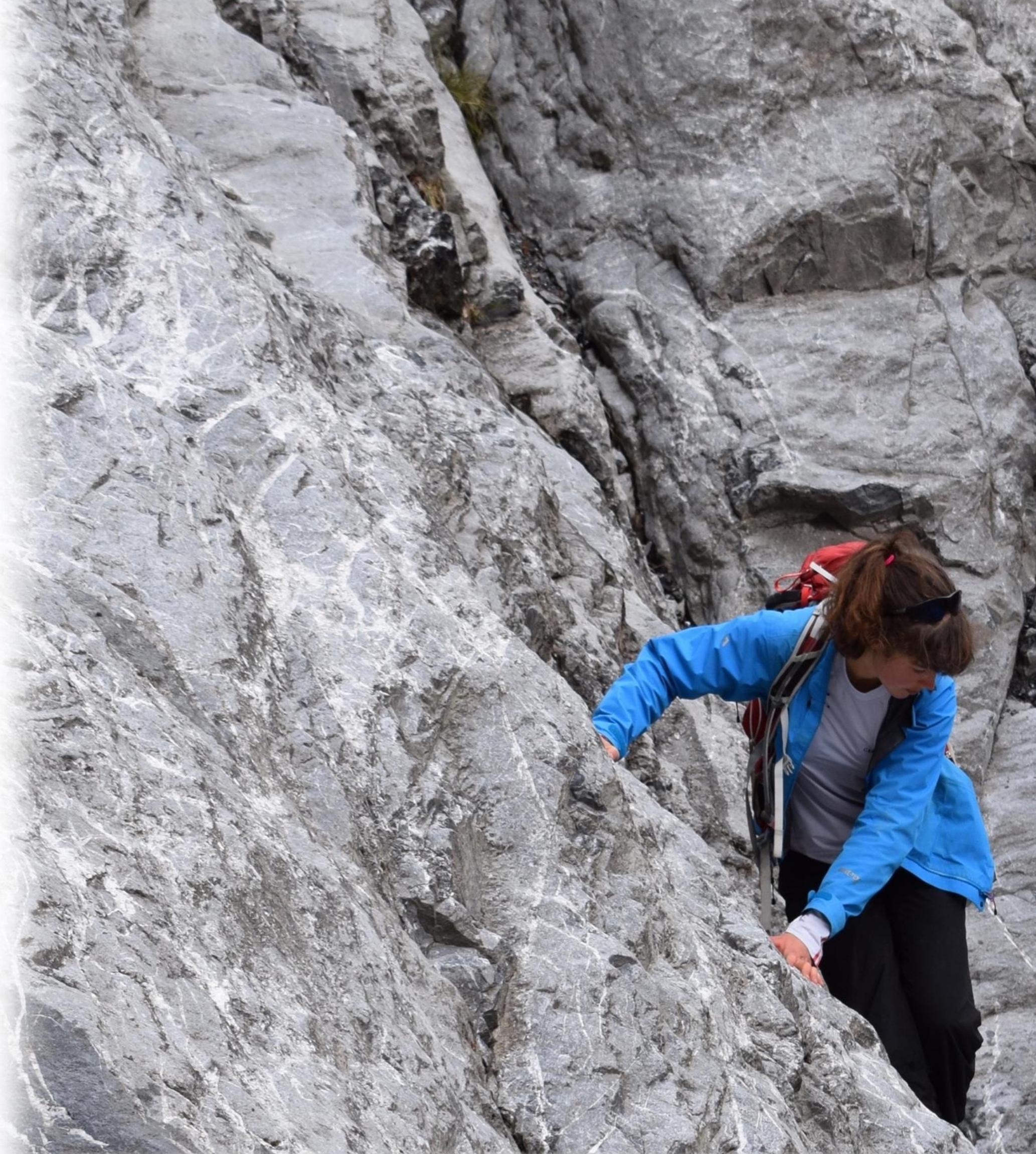




\title{
A report on gender diversity and equality at Tectonic Studies Group (TSG) meetings: 2007-2019.
}

\author{
Compiled by Alodie Bubeck ${ }^{1}$ and Natalie Farrell ${ }^{2}$. \\ ${ }^{1}$ School of Geography, Geology \& the Environment, University, of Leicester, Leicester. LE2 7RH. UK. \\ ${ }^{2}$ School of Geosciences, University of Aberdeen, Aberdeen. AB24 3UE. UK. \\ Contact:ab753@le.ac.uk and natalie.farrell@abdn.ac.uk
}

The Tectonic Studies Group (TSG) is a specialist group of the Geological Society of London that was founded in 1970 as a forum for discussion of research in structural geology and tectonics. Here, we report on gender diversity and equality at the TSG annual conferences between 2007 and 2019. Gender diversity was analysed in the following categories: 1.) talks presented; 2.) posters presented; 3.) session chairs (invited); 4.) keynote speakers (invited); 5.) TSG prize winners and judges; and 6.) organizing committees.

From 2007-2019 we observe an increase in the proportion of women presenting their research at TSG meetings across the period, from $20 \%$ in the 2000 s, to $34 \%$ in the late 2010 s. The average proportion of women delivering talks at TSG meetings has almost doubled, from 17\% in 2007 to $30 \%$ in 2019. Further, the average proportion of women presenting posters has increased from $26 \%$ in the 2000 s to $40 \%$ in the late 2010s. Women, however, remain underrepresented at TSG meetings. On average, submissions from women account for $30 \%$ of submitted abstracts. Women are also consistently underrepresented as keynote presenters, session chairs, and winners of TSG prizes.

We outline a series of recommendations for future committee members, meeting and fieldtrip organizers, and the community as a whole, that aim to achieve equitable gender representation at meetings, and for other underrepresented groups at TSG meetings. 
Front cover: NERC CDT student Lauren Kedar investigating fractured carbonates in the French Alps. Photo Clare Bond.

\section{Acknowledgements}

The authors would like to thank the following individuals for their support in creating this report, including commenting on early drafts, input into recommendations, and the encouragement to put it all together: Atle Rotevatn (University of Bergen), Clare Bond (University of Aberdeen), Dave Healy (University of Aberdeen), Richard Walker (University of Leicester). 
Here, we report on the gender split of presenters, session chairs, keynote speakers, prize winners and conference organizers at TSG conferences between 2007-2019. Relevant data was compiled from TSG conference programmes from 2007-2019, which are available on the TSG website ${ }^{1}$. Individuals were identified using personal contact, university or company webpages, and social media accounts. Gender diversity was analyzed in the following categories:

1. Talks presented

2. Posters presented

3. Session chairs (invited)

4. Keynote speakers (invited)

5. TSG prize winners and judges (Ramsay Medal, Best Talk, Best Poster, and Best Overall Presentation; where data are available).

6. Organizing committees (where data available)

Data for each category were analyzed and plotted as percentages of the total number of delegates at each meeting, and as values normalized by the number of male and female attendees at each meeting. Summary plots for each of the categories are shown below.

In this report, we only consider binary gender diversity and equality because this is the only data currently available. We do not have data on any other aspects of diversity, such as age, ethnicity, sexual orientation, or disability. In addition, there is no record of the career level of presenters at the meetings and these aspects are not discussed further in this report. We acknowledge that this analysis is not complete, or an ideal representation of the complete diversity of TSG meetings, but we hope that sharing this data, and highlighting the challenges that the TSG faces, will be a good starting point. We end by setting out recommendations for future meetings to ensure inclusion and access for all participants at future TSG meetings.

\footnotetext{
${ }^{1}$ https://tectonicstudiesgroup.org
} 


\section{Previous meetings}

The size of TSG conferences (based on total number of oral and poster presentations) shows some minor variation between 2007-2019, but the average number of presentations given at meetings during this period (excluding the joint assembly with the VMSG and BGA in 2017) is 87 (Figure 1). The following years are considered smaller than average TSG meetings: 2008, 2009, 2010, 2014.

TSG Meeting Size: 2007-2019

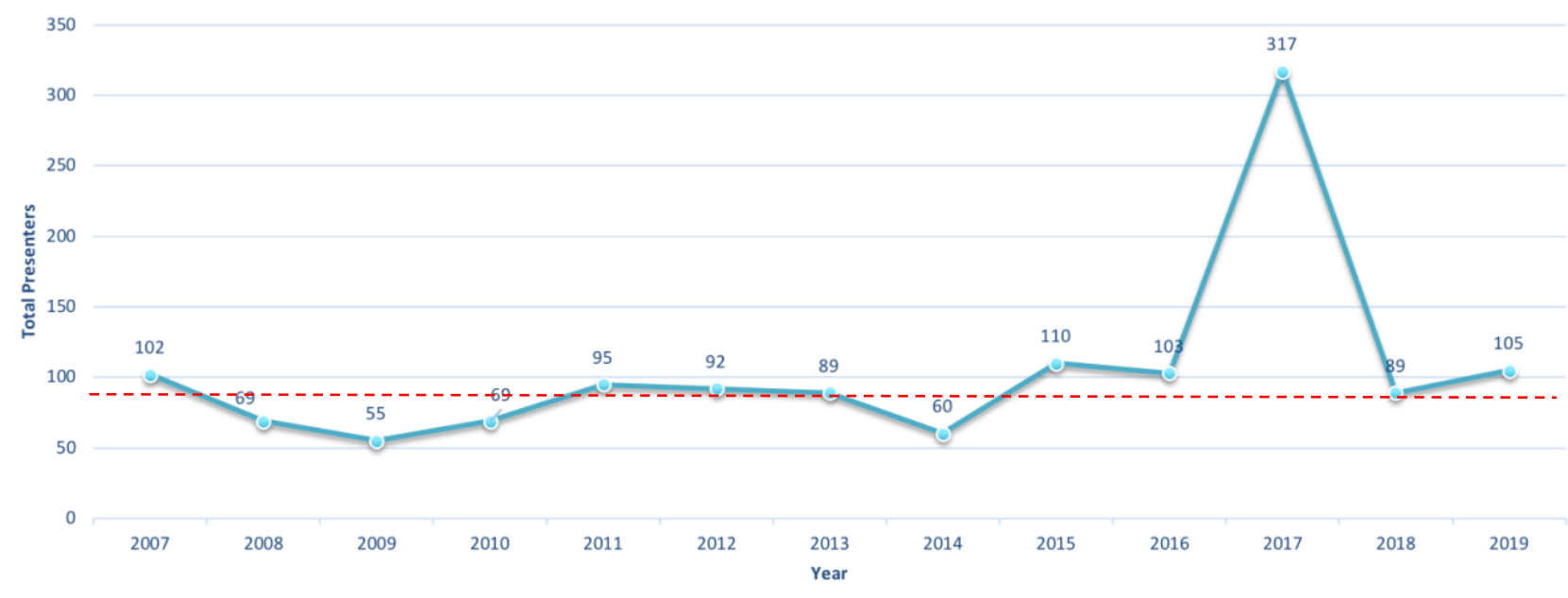

Figure 1. Total number of presentations (talks and posters) delivered at TSG meetings between 2007-2019. In 2017, the TSG held a joint assembly with the VMSG and BGA, resulting in a significant increase in the number of contributions (317). Dashed red line indicates the average size of TSG meetings during the period 2007-2019 (excluding 2017).

\% of TSG Presentations by Type: 2007-2019

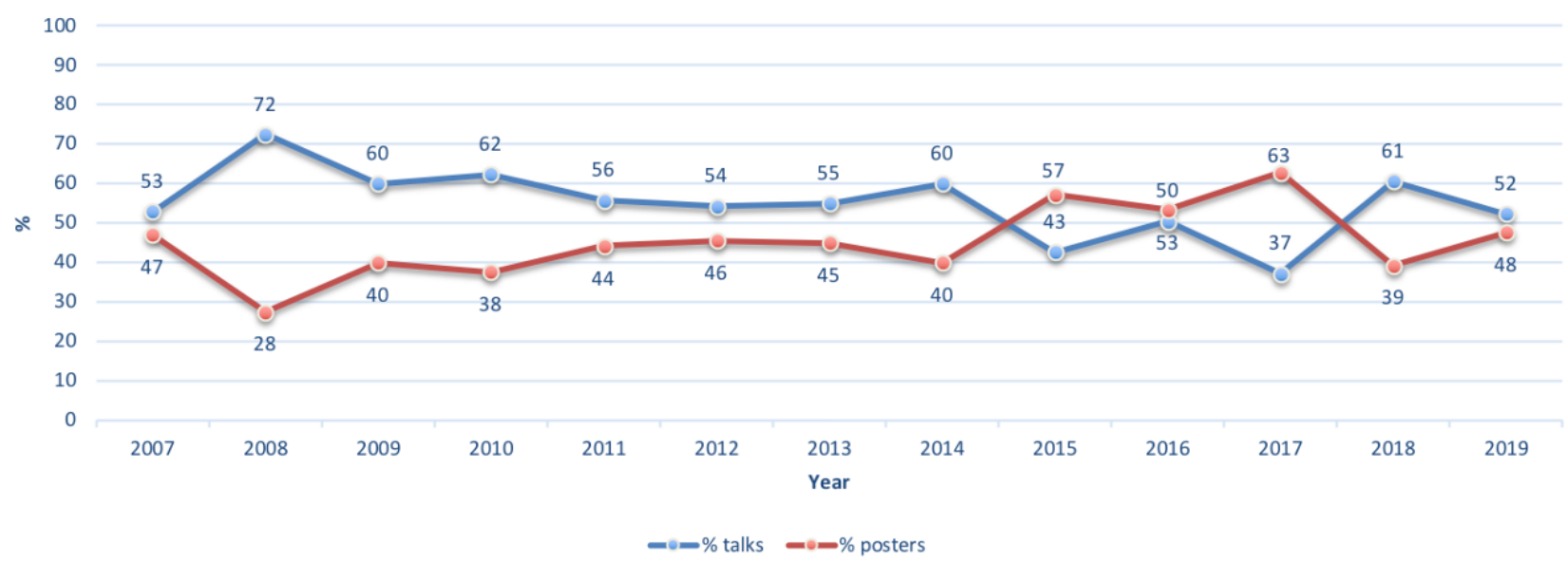

Figure 2. Percentage of talks and poster presentations that were delivered at TSG meetings between 20072019.

Presentations at TSG meeting most commonly feature a greater number of talks than posters (Figure 2). The percentage of oral presentations range from 72\% (2008) to 52\% (2019). Notably, in 2015, 2016 and 2017, meetings were larger than the average (Figure 1) and featured a greater proportion of poster presentations: $57 \%, 53 \%$, and $63 \%$, respectively. 
Although values fluctuate slightly year by year, the proportion of women presenting their research at TSG meetings shows an overall increase over 12 years, from 18 contributions from women in 2007 (out of 102 total) to 28 in 2019 (out of 105) (Figure 3).

N.B. There were a small number of presenters at each meeting who could not be identified by the authors of this report, or from university webpages or social media accounts. These make up 2-3\% of presenters and have been excluded from the analysis.

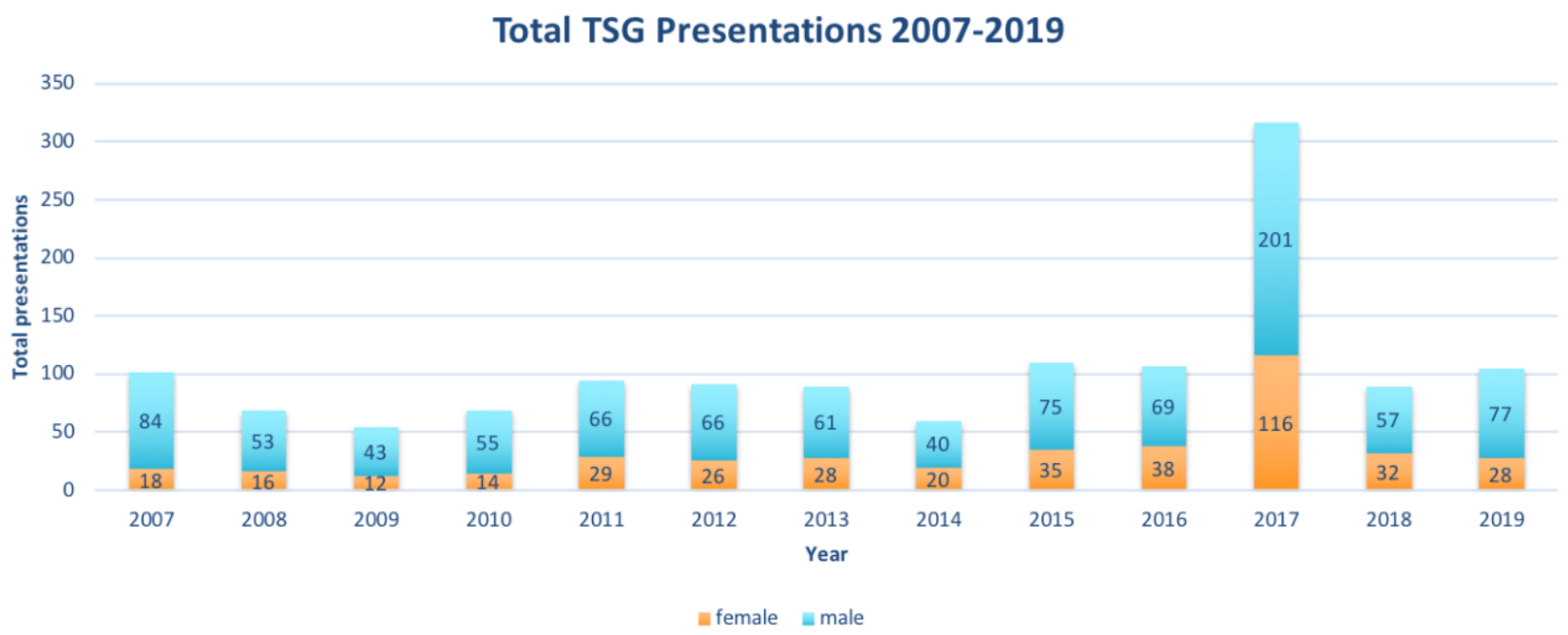

Figure 3. Total presentations at TSG meetings from 2007-2019, split by gender.

\section{Total Oral Presentations}

We observe that the proportion of women listed on the programmes as oral presenters has increased from $\mathbf{1 7 \%}$ in 2007 to $\mathbf{2 4 \%}$ in 2019 (Figure 4). The percentages have remained relatively steady at 20-30\% since 2011. The ratio of male/female speakers, however, is consistently high across the meetings, but it is important to note that these values may be skewed by lower overall submissions from women compared to men.

\section{TSG Oral Presentations}

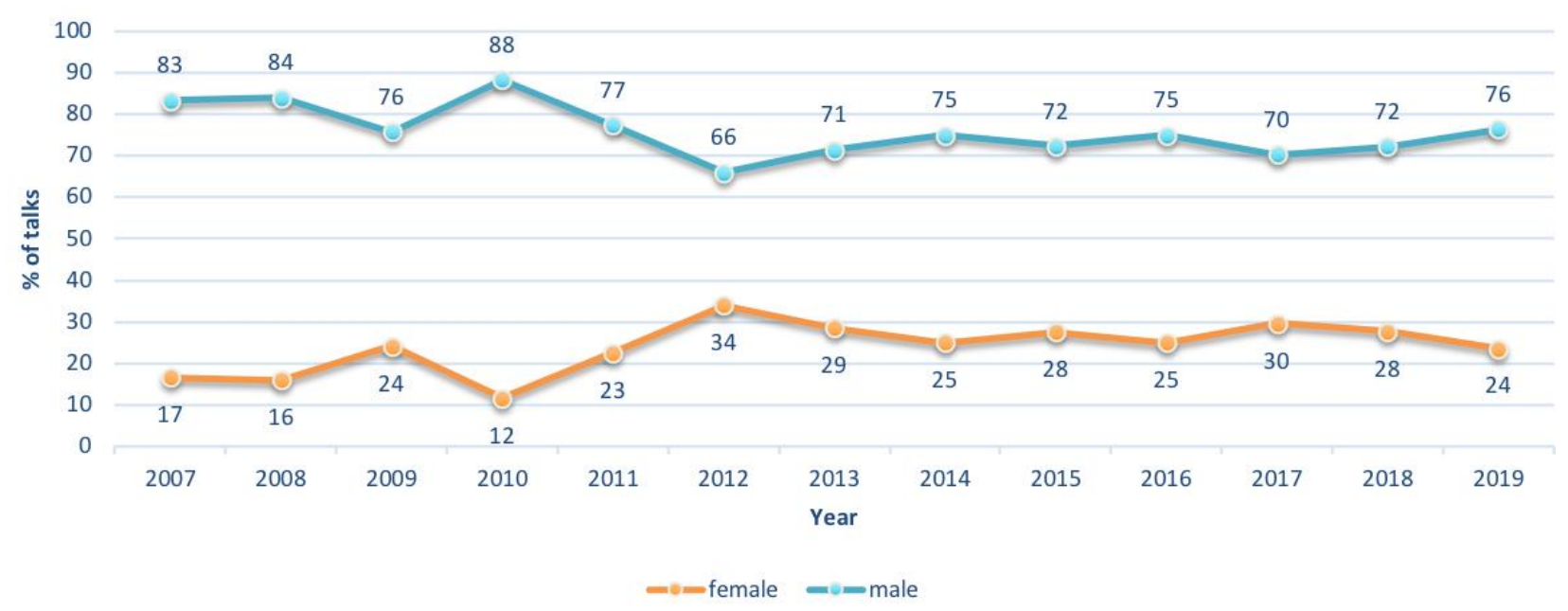

Figure 4. Gender split for oral presentations at TSG meetings from 2007-2019, as percentage values. 
On average, oral presentations delivered by women comprise $24 \%$ of all talks delivered during the period 2007-2019.

\section{Total Poster Presentations}

Although the proportion of women presenting posters shows a fairly steady increase from $19 \%$ in 2007 to 49\% in 2018 and 30\% in 2019, these values track consistently behind those of men (Figure 5). On average across 12 years, poster presentations delivered by women comprise 35\% of posters delivered whilst $65 \%$ are presented by men.

TSG Poster Presentations

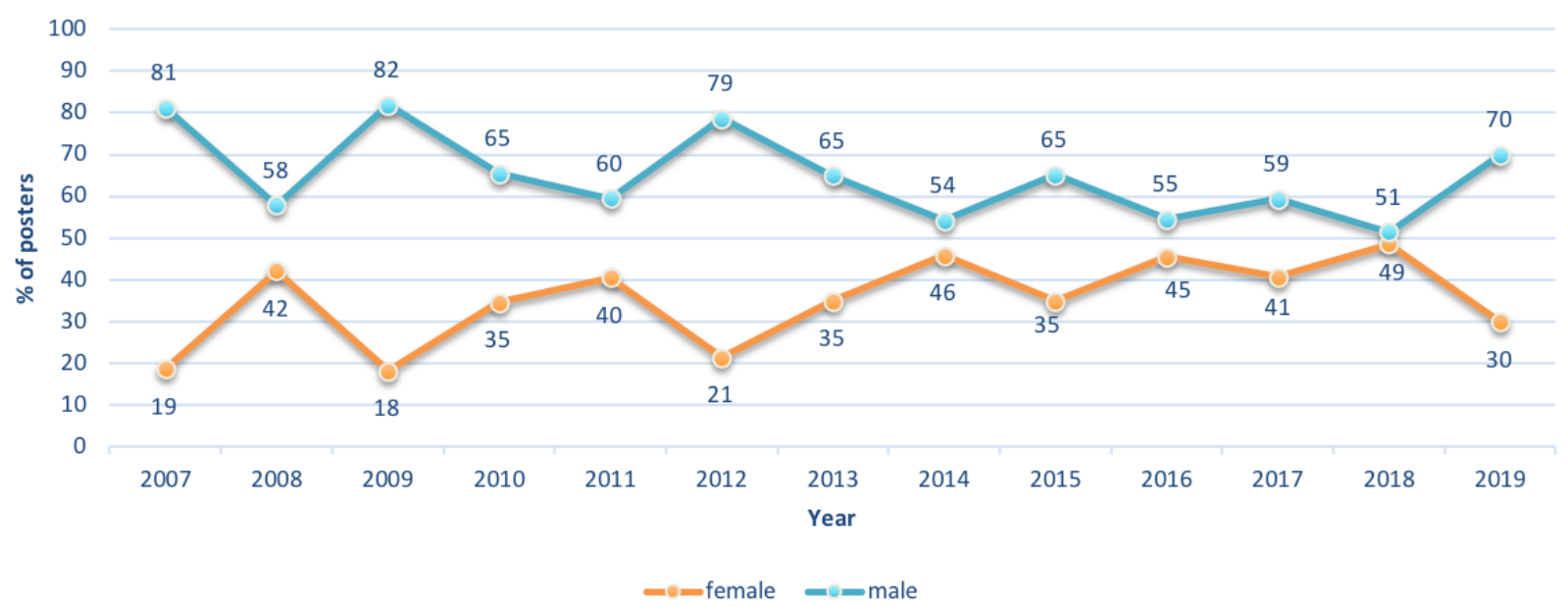

Figure 5. Gender split for poster presentations at TSG meetings from 2007-2019, as percentage values.

To remove year-year fluctuations in gender differences when considering presentations, a 4-year moving average has also been calculated for all presentations, and talks and poster presentation categories (Table 1).

\begin{tabular}{|l|c|c|c|c|c|c|}
\hline Moving average window & $\begin{array}{c}\mathbf{2 0 1 9 -} \\
\mathbf{2 0 1 5}\end{array}$ & $\begin{array}{c}\mathbf{2 0 1 7 -} \\
\mathbf{2 0 1 4}\end{array}$ & $\begin{array}{c}\mathbf{2 0 1 5} \\
\mathbf{2 0 1 2}\end{array}$ & $\begin{array}{c}\mathbf{2 0 1 3 -} \\
\mathbf{2 0 1 0}\end{array}$ & $\begin{array}{c}\mathbf{2 0 1 1} \mathbf{2 0 0 8} \\
\mathbf{2 0 1 0}-\end{array}$ \\
\hline Total female presenters (\%) & 34 & 35 & 31 & 28 & 25 & 20 \\
\hline Total male presenters (\%) & 66 & 65 & 69 & 72 & 75 & 80 \\
\hline Talks presented by women (\%) & 27 & 28 & 25 & 25 & 18 & 17 \\
\hline Talks presented by men (\%) & 73 & 72 & 75 & 75 & 82 & 83 \\
\hline Posters presented by women (\%) & 40 & 41 & 33 & 33 & 35 & 26 \\
\hline Posters presented by men (\%) & 60 & 59 & 67 & 67 & 65 & 74 \\
\hline
\end{tabular}


Table 1. 4-year moving average of male and female presenters (overall), and presenters of talks and posters at TSG meetings during the period 2007-2019.

In table 1, we observe a clear increase in the proportion of women presenting their research at TSG meetings across the period, from $20 \%$ in the 2000 s, to $34 \%$ in the late 2010 s. We also observe that the average proportion of women delivering talks at TSG meetings has almost doubled, from 17\% in 2007 to 30\% in 2019. Further, the average proportion of women presenting posters has increased from $26 \%$ in the 2000 s to $40 \%$ in the late 2010 s.

\section{Normalized Oral Presentations}

Oral presentation data was normalized to account for 'presentation allocation relative to applicant gender' i.e. the number of people from each gender presenting at the conference. When normalized by the total number of women or men presenting at a meeting (Figure 3), we find that the proportion of women presenting talks, instead of posters, shows some consistency at 50\% in 2007 to $46 \%$ in 2019. Broadly, the normalized data shows that oral presentations by women decreased from an average of 52\% between 2007-2009, 47\% between 2010-2014, to 38\% between 2015-2019 (Figure 6). In the same time periods, the normalized data shows that oral presentations by men also decreased from an average of 66\% between 2007-2009, 61\% between 2010-2014, to 53\% between 2015-2019 (Figure 6).

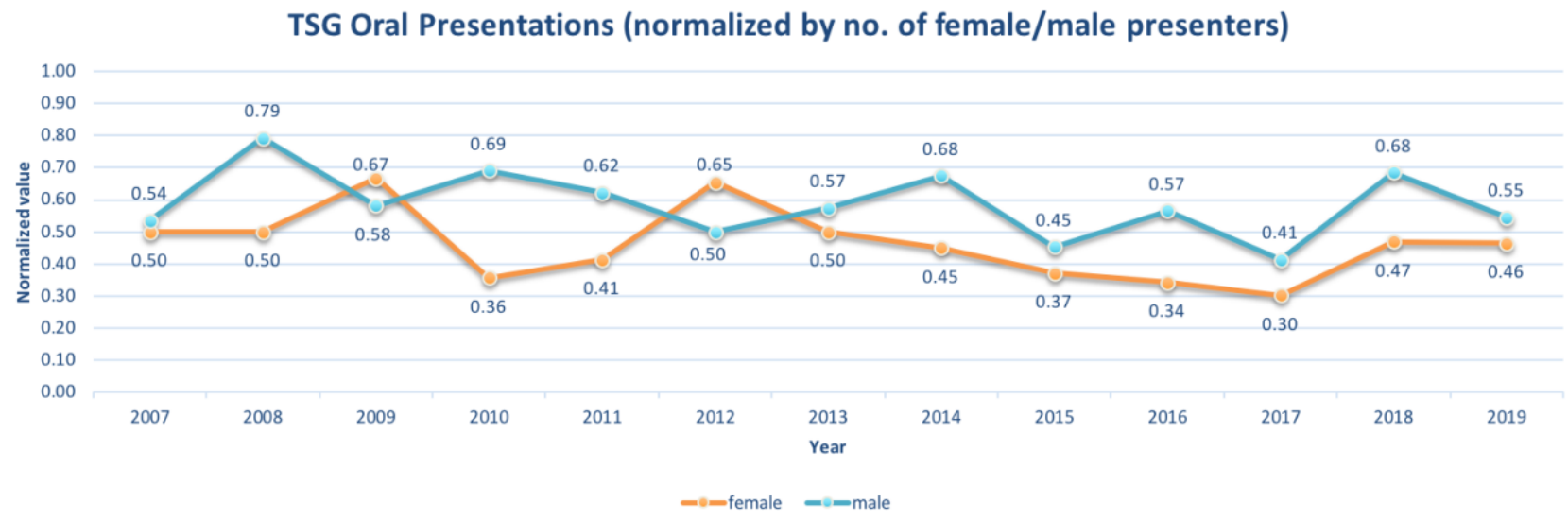

Figure 6. Normalized gender split for oral presentations at TSG meetings from 2007-2019. Values are normalized by the total number of women or men attending each presenting.

In 2012 and 2009, we note that more women delivered talks than posters. In 2019, 2018, 2013, 2008, and 2007 there was a near 50:50 split in women delivering talks and posters. Based on the normalized values, $47 \%$ of female presenters, on average, have delivered talks, whereas, $60 \%$ of male presenters, on average, delivered talks at TSG meetings.

\section{Normalized Poster Presentations}

Based on the normalized values (Figure 7), on average $55 \%$ of female presenters have delivered posters. In contrast, $40 \%$ of male presenters have delivered posters at TSG meetings. Over a 12-year period, trends show a $10 \%$ increase in the average number of posters presented by women from an average of $44 \%$ between 2007 2009, 53\% between 2010-2014, to 61\% between 2015-2019 (Figure 7). In the same time periods, the 
normalized data shows that oral presentations by men also increased from an average of $33 \%$ between 2007 2009, 39\% between 2010-2014, to 46\% between 2015-2019 (Figure 7).

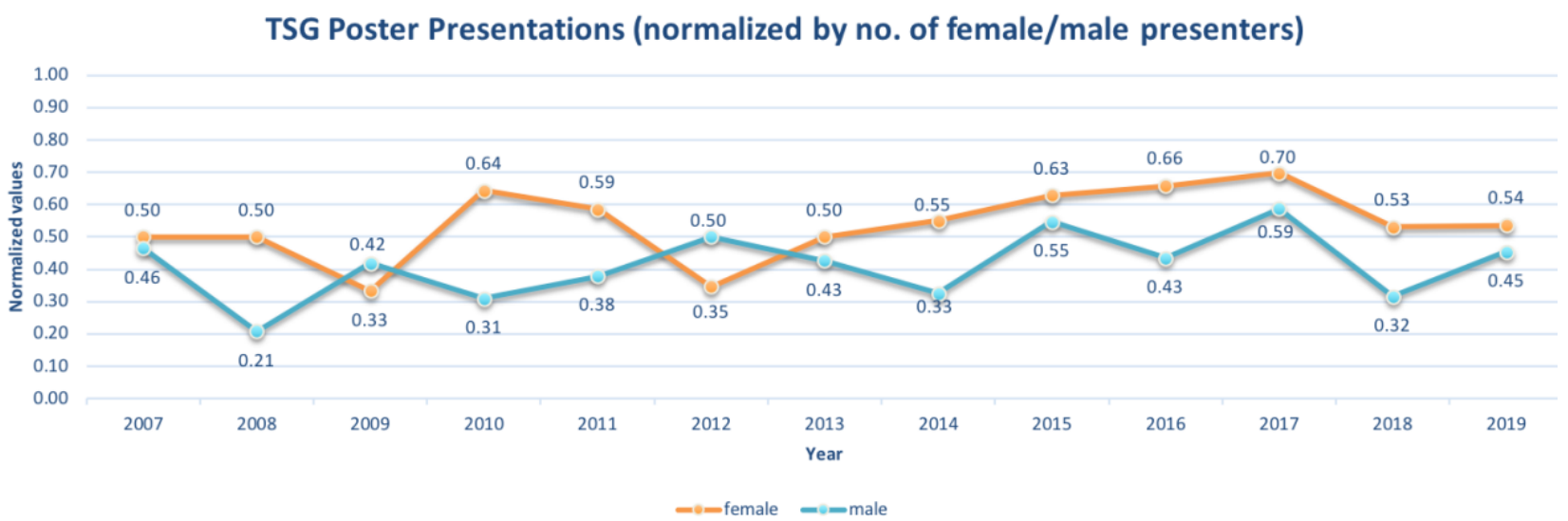

Figure 7. Normalized gender split for poster presentations at TSG meetings from 2007-2019. Values are normalized by the total number of women or men presenting each meeting.

No strong correlation exists between meeting size and contributions from women. In 2016 (total of 121 presentations), abstracts from women accounted for $36 \%$ of the programme. For the smaller meetings 2008 2010 (69, 55, 69 presentations, respectively; see table 2), for instance, schedules were more male-dominated with women making up $\sim 20 \%$ of presenters. This is not always the case however; in 2018, there were a total of 89 presentations, and women comprised 36\% of presenters. In contrast, there were a total of 105 presentations in 2019, and women comprised 27\% of presenters (table 2). On average across the period, 29\% of all presenters at TSG meetings have been women. 


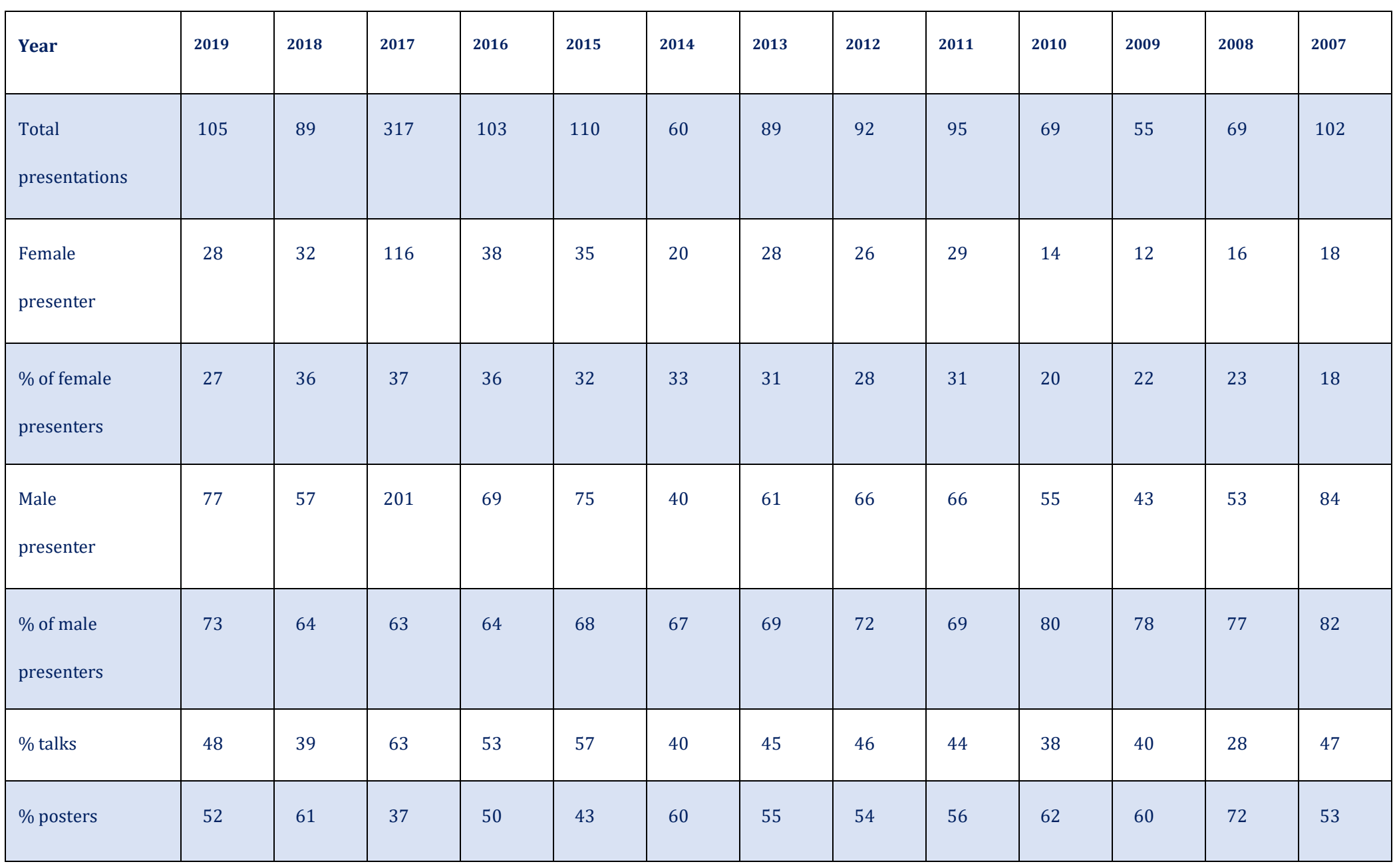

Table 2. Summary of data from meetings between 2007-2019. 
Additionally, no strong correlation exists between the proportion of female presenters and the most common types of presentations being delivered at each meeting. In the years 2007-2014, meetings featured a greater number of poster presentations than talks ( $<50 \%$ talks; Figure 2). During this interval, we see an increase in the percentage of female presenters from $18 \%$ to $~ 33 \%$ (Table 2). For meetings in years 2015-2018, meetings featured a greater proportion of talks ( $>50 \%$; Figure 2$)$. The percentage of female presenters at these meetings shows a continued increase to $\sim 40 \%$ (Table 2 ).

In 2019, there was an approximately even split between the number of oral and poster presentations but the proportion of presentations delivered by women was lower than preceding years (27\%). It is not clear why this is the case.

\section{Session Chairs}

For meetings with available data, women historically comprise a small number of session chairs (Figure 8). Across the meetings, we find that, on average, $80 \%$ of session chairs are men, and $20 \%$ are women. For the last two meetings, for which there are data (2017 and 2019), we note an improvement in the proportion of women chairing sessions: $35 \%$ and $45 \%$, respectively.

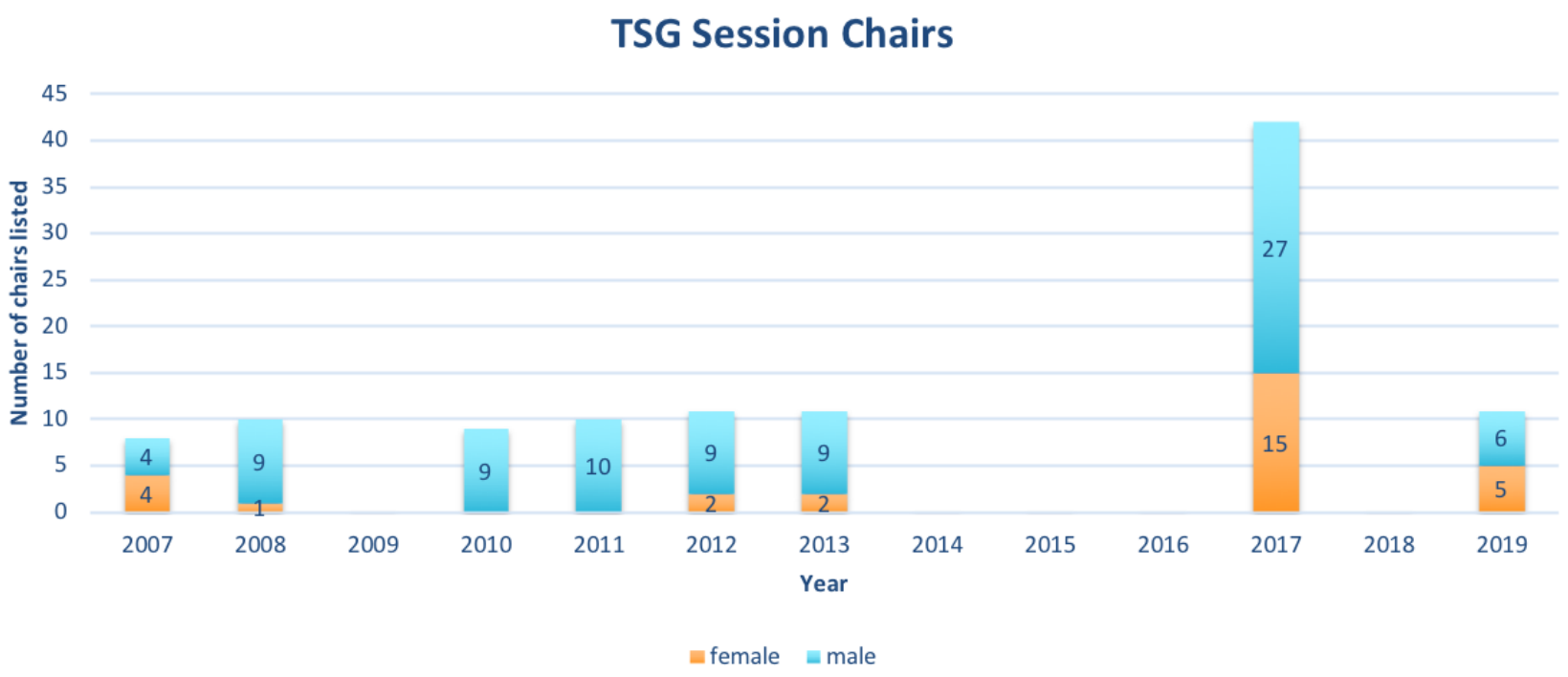

Figure 8. Gender split for session chairs at TSG meetings from 2007-2019.

\section{Invited Keynote Speakers}

Women are also historically underrepresented as invited keynote speakers at TSG meetings (Figure 9). Until 2019, no more than 1 woman was invited to give a keynote presentation at any TSG meeting, and frequently, none were invited. In 2019, 3 of the 5 keynote talks were presented by women. 


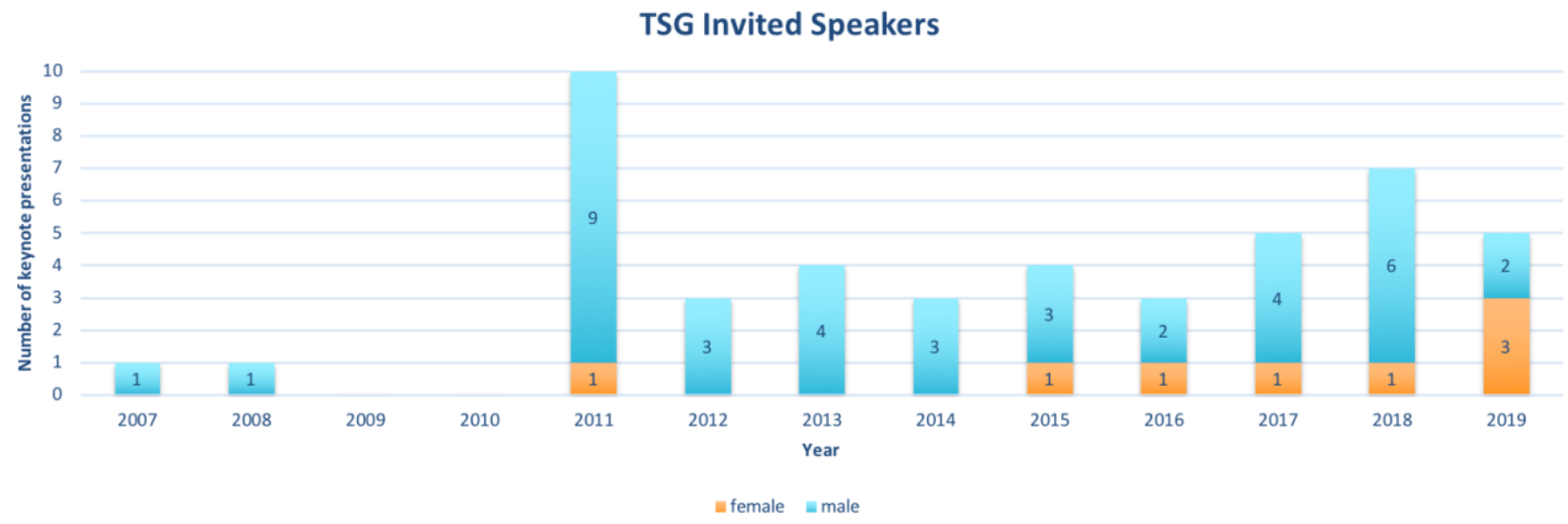

Figure 9. Gender split for invited speakers at TSG meetings from 2007-2019.

\section{Conference Organizing Committees}

Based on available data (years: 2007, 2009, 2010, 2013, 2014, and 2017) organizing committees are also historically male-dominated. On average across these years, women represent $13 \%$ of organizers.

\section{TSG Organizing Commitees}

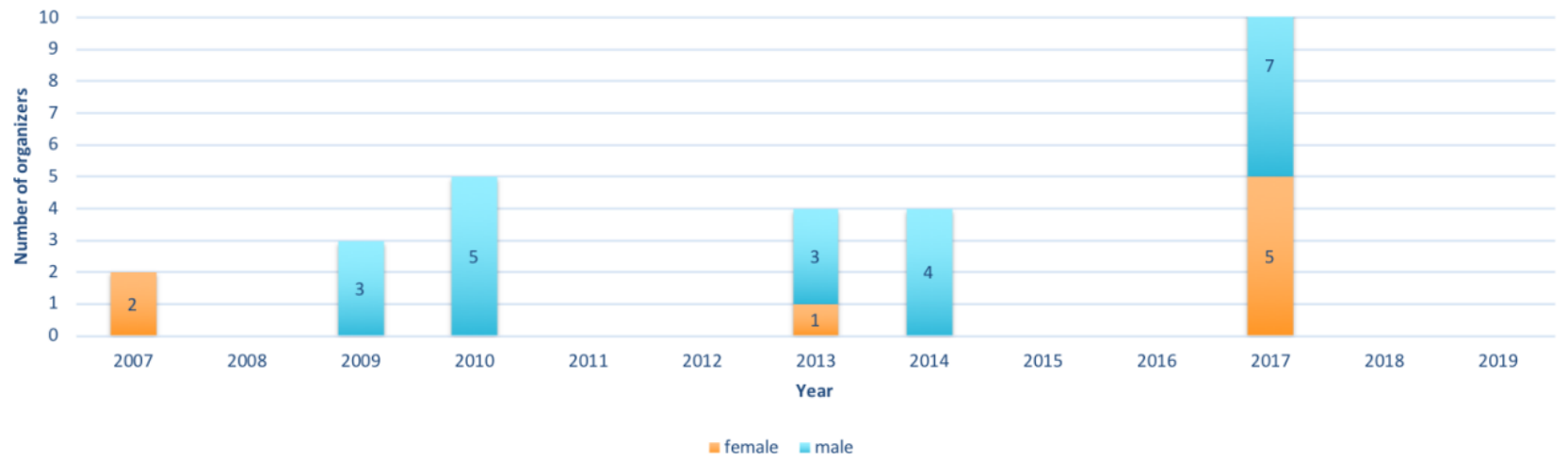

Figure 10. Gender split for organizing committees of TSG meetings from 2007-2019. Data are only available for 6 of the 13 meetings.

\section{Prizes}

9.1. Ramsay Medal: Winner of the prize are historically male-dominated ( 3 women in $\mathbf{1 3}$ years). We also observe, however, that nominees are also male-dominated: between 2016-2019 nominations for male PhD students account for 60\% (2016); 64\% (2017); 82\% (2018); and 83\% (2019). For available records (2016-2019), male to female judge ratios vary: 3:0 in 2016 (female winner); 6:2 in 2017 (male winner); 3:2 in 2018 (male winner); and 2:3 in 2019 (male winner).

9.2. Mike Coward prize for best talk: Data available for 11 of the 13 meetings, show that there have been 3 female winners. Male to female best talk judge ratios vary for the last 4 years, for which data exists (1:2 in 2019 (male winner); 4:1 in 2018 (female winner); 3:5 in 2017 (male winner); and 4:0 in 2016 (female winner)). 


\section{3. $\mathrm{BP} /$ Shell prize for best overall presentation (poster or talk): There have been no female}

winners of the best overall presentation in 13 years. Judging of the best overall presentation is done jointly by poster and talk judges. Data are available from 2016-2019 only (see above and below).

9.4. Sue Treagus Prize for best poster: Using available records of 10 best poster winners, 4 prizes have been awarded to women. Male to female judge ratios for meetings in 2019-2016 vary from: 1:4 in 2019; 2:2 in 2018; 4:2 in 2017; and 3:1 in 2016.

\section{Challenges and Future Improvement: Equity and Inclusion at TSG Meetings.}

The implicit and explicit biases that affect the participation of women in STEM subjects, as well as their representation at conferences, are well-known (e.g. Ford et al., 2018; Popp et al., 2019). Despite evidence which has demonstrated that an inclusive and participatory approach to scientific research is most effective (e.g. Campbell et al. 2013, Freeman \& Huang 2014), issues of exclusion at conferences remain very common in the geosciences.

Although we see an improvement in the number of presentation submissions from women in the years 20072019, women remain underrepresented at TSG meetings. Analysis of AGM programs from this period are dominated by men: as presenters (oral and poster), conveners and invited speakers. On average, submissions from women account for $\mathbf{3 0 \%}$ of submitted abstracts. Women are also consistently underrepresented as winners of TSG prizes. With regards to the Ramsay Medal, this underrepresentation appears to be linked to a smaller number of nominations each year for work published by women.

As a committee, we would like TSG meetings to be an overwhelmingly positive experience for everyone who attends. It is our aim to showcase the research of all scientists, and ensure that no one feels excluded when they do not see people who look like them, or due to barriers, including lack of childcare, that prevent them from participating fully. We would like future committee members and meeting organizers to adopt the following recommendations to strengthen our support of women, as well as other underrepresented groups at TSG meetings.

Please note, the following recommendations are based on the current available data and therefore relate specifically to the improvement of binary gender diversity and equality at TSG meetings.

\subsection{Committee Action.}

As a committee, we will commit to the following actions to ensure inclusion, provide access and value contributions from all participants.

- Code of Conduct: We will ensure that a copy of our Code of Conduct is clearly communicated and accessible so that expectations for appropriate behaviour at meetings, as well as TSG fieldtrips and workshops, are clearly defined.

- Prizes:

- We will encourage Ramsay Medal submissions on behalf of women when the prize is being organized and advertised (e.g. posting onto the Geotectonics mailing list and promotion on our social media accounts).

- We will make it clear on our website, and in advertising material, that papers written by $\mathrm{PhD}$ students can be nominated for the Ramsay Medal by anyone, not just by supervisors. We encourage nominators, who are not a supervisor of the student, to liaise with the supervisor(s) in this instance.

- We will organize as diverse a group of people to act as prize judges, as is possible. This includes asking people from a range of career levels to be judges. 


\section{- Future data collection:}

- Monitoring future progress in equity and inclusion will require the collection of data from TSG participants. We will look at options to gather this data on all forms of diversity, as well as the career stage of presenters and statistics on requested Vs allocated presentations. We will present these ideas at next AGM for discussion with the community.

- We will also discuss policies regarding the collection, organization, storage, and presentation of such (anonymous) datasets. For example, organizers could collect the information as part of a registration form, which includes a statement explaining how we intend to use the data, and send this to the committee to collate.

- Provide recommendations and advice to organizers on ensuring diversity at TSG meetings, through our TSG organizer's guide document.

\subsection{Recommendations to Organizers.}

We will ask future organizers to do the following:

- Presentation schedule: Organizers should make a proactive commitment to producing as diverse a group of potential speakers as possible.

- To overcome some of the challenges associated with this, organizers should add a statement to their abstract submission information and/or webpage, encouraging women to request oral presentations. If the diversity of speakers is low following the submission deadline, organizers should consider contacting authors who submitted posters and invite them to give talks.

- Session chairs: Organizers should arrange an approximately equal number of female and male session chairs. We also encourage organizers to give opportunities to early-career stage researchers to convene sessions. Organizers could consider adding a box to their registration form which asking if the attendant is willing to act as a session chair.

- Keynote speakers: We recommend that the organizers invite keynote speakers, and that the group of speakers invited are as diverse as possible. We also encourage organizers to actively seek young, talented scientists and communicators as keynote speakers. It should always possible to find brilliant keynote presenters of different gender/age/background.

- Organizing committees: When building their organizing committee, we ask organizers to invite a diverse group of volunteers. For departments where diversity is low, organizers should consider inviting people from other institutions, or outside their typical networks to assist.

- Childcare facilities: Where possible, we ask organizers to arrange for childcare facilities to be available to attendees with families, and for these facilities to be advertised well in advance of the abstract submission deadline. This may also reduce the number of declined invitations from women (and men), who have increased demands on their time.

- Single-day registration options: Where possible, we ask organizers to provide this option, which may appeal to people with care responsibilities who wish to attend but cannot afford multiple days away from home. The option should be advertised broadly to give people with caring responsibilities time to decide if they wish to attend.

- Code of Conduct: We ask organizers to share a copy of the TSG Code of Conduct on their registration site, alongside the registration documents.

\subsection{Help from the structural geology and tectonics community}

Finally, it is our hope that the above steps will improve in the visibility of women in specific categories (e.g. session chairs, keynote speakers, judges) and, therefore, contribute to an improvement in overall female 
participation in future TSG meetings. However, to succeed in our efforts, we will also need the support of the TSG community. To you we request:

- Encourage and facilitate female students and ECRs to attend TSG meetings, and deliver oral presentations, if they wish to do so.

- Nominate female PhD students for the Ramsay Medal.

- Share your feedback and ideas at the annual meeting (AGM), either in person or via email to the TSG Chair/Secretary prior to the meeting.

\subsection{References}

1. Campbell, L.G., Mehtani, S., Dozier, M.E. and Rinehart, J., 2013. Gender-heterogeneous working groups produce higher quality science. PloS one, 8(10), p.e79147.

2. Ford, H.L., Brick, C., Blaufuss, K. and Dekens, P.S., 2018. Gender inequity in speaking opportunities at the American Geophysical Union Fall Meeting. Nature communications, 9(1), p.1358.

3. Freeman, R.B. and Huang, W., 2014. Collaboration: Strength in diversity. Nature News, 513(7518), p.305.

4. Popp, Andrea, Stefanie R. Lutz, Sina Khatami, Tim van Emmerik, and Wouter J. Knoben. 2019. Perceptions and Impacts of Gender Inequality in the Geosciences Are Strongly Gendered. EarthArXiv. April 1. doi:10.31223/osf.io/3jkcp. 